\title{
Capoeira Angola e suas relações com o mito da democracia racial brasileira
}

\section{Capoeira Angola and its relations with the myth of Brazilian racial democracy}

\author{
Gabriela Balaguer $^{1}$
}

\begin{abstract}
Resumo
A capoeira é manifestação cultural largamente conhecida pelos brasileiros e estrangeiros, como parte da cultura e identidade brasileiras. Entretanto, sendo cultura popular negra deve ser compreendida na sua relação com a cultura dominante, em que estão presentes elementos de resistência e consentimento (HALL, 2013). No século XIX e início do XX, a capoeira foi intensamente reprimida pelo Estado, afastando racial e etnicamente o negro da construção da identidade nacional (REIS, 2000). Na década de 30 , uma nova narrativa de identidade brasileira, conhecida como democracia racial brasileira, valorizou a integração cultural e biológica das três raças no Brasil (SCHWARZ, 2012; MUNANGA, 1996). Junto às outras manifestações culturais e religiosas, a capoeira é valorizada e integrada ao Estado (PIRES, 2010). O texto pretende trazer apontamentos para se reavaliar o modo de relacionamento da capoeira angola com as questões raciais e étnicas, a partir do questionamento do mito da democracia racial e das contribuições dos estudos culturais (MUNANGA, 1996; CARONE; BENTO, 2002; HALL, 2013).
\end{abstract}

Palavras-chaves: Cultura popular. Capoeira. Democracia racial.

\begin{abstract}
Capoeira is a cultural manifestation widely known as part of Brazilian identity and culture both by Brazilians and foreigners. Nevertheless, for being originally a black popular culture, it must be understood in relation to the dominant culture, where elements of resistance and consent are present (HALL, 2013). In the nineteenth and in the beginning of the twentieth century, capoeira was strongly repressed by the State, driving the blacks away from the construction of national identity based on racial and ethnic grounds (REIS, 2000). In the 30's, a new narrative of Brazilian identity, known as Brazilian racial democracy, treasured the cultural and biological integration of the three existing races in Brazil (SCHWARZ, 2012; MUNANGA, 1996). Along with other cultural and religious manifestations, capoeira is now valued and integrated into the State (PIRES, 2010). The text aims at raising aspects that allow a reappraisal of how the Angola capoeira relates to racial and ethnic issues, based on questioning the myth of racial democracy and the contribution of cultural studies (MUNANGA, 1996; CARONE; BENTO, 2002; HALL, 2013).
\end{abstract}

Keywords: Popular culture. Capoeira. Racial democracy.

1 Doutoranda do Departamento de Psicologia Escolar e Desenvolvimento Humano, do Instituto de Psicologia da USP. Professora Colaboradora da UNESPAR. E-mail: gabibalaguer@usp.br 


\section{Introdução}

A primeira vez em que me recordo de ter visto uma roda de capoeira foi aos dezoito anos, em Lençóis, na Bahia. Antes disso, não possuo nem um registro mnemônico consciente. O que eu vi, eram homens negros reunidos em círculo, alguns tocando instrumentos como berimbau, pandeiro e atabaque, um entoando um canto, outros respondendo a cantiga, duas pessoas no centro, movimentando-se de modo coordenado e com extrema destreza corporal àquela musicalidade. Não me recordo da presença de brancos e de mulheres. Se havia, sua presença foi apagada da imagem principal que retive, como presenças secundárias, menos importantes, adjacências. Eis que faço a pergunta, com a qual começo esse texto: o que eu via?

Todos aqueles elementos já possuíam uma série de significados e sentidos informados muito antes de estar ali. A roda de capoeira não era um fenômeno estranho seja na forma de sua configuração, seja em alguns de seus significados. Ao contrário, a roda de capoeira já era um signo complexo organizado em torno de muitos elementos e bastante familiar. Eu, como brasileira, sabia nomeá-la, identificar seus elementos constituintes, enfim reconhecê-la em seus traços gerais.

Para o espectador brasileiro e ingênuo, sem nenhuma informação e formação sobre a história da capoeira, seus estilos ou modalidades ou o processo do ritual da roda de capoeira, a identificação de que certo tipo de manifestação cultural se trata de capoeira passa pela configuração de uma gestalt ou dos elementos que a constituem. Essa gestalt foi constituída de diversas formas: nos livros didáticos de história do
Brasil, nas diversas mídias (impressas, televisivas e virtuais), na e pela literatura de Jorge Amado, especialmente, e na vasta produção musical brasileira (samba, bossa nova, tropicalismo e rap). As pinturas de Rugendas e Carybé, as fotos de Verger, os filmes de ficção, dos mais antigos e menos célebres (O Pagador de Promessas, Quilombo, Ganga Zumba) aos mais recentes e informados pela indústria cultural ${ }^{2}$ (Ó Paí, Ó e Besouro), as telenovelas e séries brasileiras (cito algumas, como Gabriela, cravo e canela, Tenda dos Milagres, Sinhá Moça e Lado a Lado), além das conhecidas apropriações musicais dos ritmos, cantigas e instrumentos próprios da capoeira como berimbau são alguns dos modos como se tem alimentado e formado o imaginário nacional acerca da capoeira na sociedade brasileira.

A imagem da roda de capoeira, formada por tocadores de diversos instrumentos, especialmente berimbaus, jogadores ao centro da roda e espectadores demarca a percepção do que seja a capoeira. Não é nem necessário que todos os elementos constituintes dessa gestalt compareçam para que esses significados préengendrados apareçam. Certa movimentação corporal típica, que vai desde movimentos com as mãos nos chãos, movimentos de pé, a saltos acrobáticos bem como a presença de instrumentos como berimbau e certa musicalidade são elementos constituidores dessa forma. ${ }^{3}$ A esse signo perceptivo, completo ou incompleto, se associam significados bastante fixados: de que se trata de luta-dança-jogo dos negros e herança da escravidão. Boa parte das imagens veiculadas sobre a roda de capoeira insistem na preservação desses significados: homens negros formando a roda em contextos e situações que se referem aos aspectos marciais e/ou culturais da manifestação. Essa representação preenche a imaginação e a

2 Há ainda algumas produções estrangeiras em que aparecem cenas da capoeira menos vinculadas à cultura e, mais, aos aspectos de luta e combate.

3 Rapidamente, o espectador brasileiro identifica que se trata de capoeira, mesmo quando existe apenas um capoeirista treinando, ou quando existem dois capoeiristas jogando sem auxílio de qualquer elemento musical, ou ainda, quando é apenas o berimbau e a musicalidade que comparecem. 
percepção tanto do brasileiro como do estrangeiro que passa pelo país. ${ }^{4}$

Bosi (2003) insiste no quanto a percepção e ação podem sofrer, por influência das mediações culturais, um processo de estereotipia, fixando significados a certas percepções, e impedindo sua aventura. Aventura estrategicamente vigiada e perseguida pela cultura dominante que pretende restringir e controlar formas de ver, sentir e querer. A percepção é vastamente mediada por discursos sociais e históricos que podem oferecer significados enrijecidos, impedindo a abertura a novos horizontes, novas significações.

$\mathrm{O}$ que se quer dizer é que a capoeira, seja a roda de capoeira, seja apenas os elementos que a constituem, tornou-se uma marca nacional, vastamente conhecida pela imaginação, memória e sensibilidade do povo brasileiro. Tal como o samba e outras manifestações culturais negras assimiladas como marcas nacionais ${ }^{5}$, a capoeira faz parte, de modo direto ou indireto, mais ou menos consciente, da formação cultural nacional. Ela atesta, em primeiro lugar, para a presença da cultura negra no país, e, em segundo lugar, para a sua integração à cultura nacional (AREIAS, 1983; FRY, 2005; PIRES, 2001; REIS, 2000, 2004; SCHWARCZ, 2012).

Naquela circunstância, ver a roda de capoeira foi como a concretização do imaginário e suas significações fixadas e facilitadas por muitas narrativas. Eu, Gabriela, branca, filha do pai da Gabriela de São Paulo, herdeira do pai da Gabriela, Ilhéus, ${ }^{6}$ estava na Bahia, terra mítica da capoeira. ${ }^{7}$
Por ora, é intenção desse ensaio olhar para outros horizontes de possibilidades que só puderam ser abertos pelo meu debruçar na convivência de mais de dez anos na Capoeira Angola (como capoeirista e pesquisadora de capoeira) e pela interlocução e reflexão trazida pela historiografia da capoeira, pelos estudos sobre o racismo no Brasil na Antropologia, Sociologia e Psicologia e, mais recentemente, pelos Estudos Culturais.

\section{AConstrução da Cultura e Identidade Nacional}

A capoeira tornou-se marca da identidade nacional, reunindo, por meio da manifestação cultural de origem negra, a suposta integração inter-racial amistosa e pacífica do povo brasileiro tanto no plano da cultura como no plano biológico. Esse processo histórico pela valorização da capoeira culminou recentemente no fato de ter se tornado Patrimônio Cultural Imaterial da Humanidade, em novembro de 2014, na nona sessão do comitê intergovernamental para salvaguarda na UNESCO (INSTITUTO DO PATRIMÔNIO HISTÓRICO E ARTÍSTICO NACIONAL, 2017). Anteriormente a isso, foi reconhecida como Patrimônio Cultural Brasileiro pelo Instituto de Patrimônio Histórico Nacional, em 2008 (FUNDAÇÃO CULTURAL PALMARES, 2016).

O processo de construção de uma cultura nacional se dá a partir de práticas discursivas do Estado que informam e organizam os sentidos, a imaginação e a memória dos sujeitos de modo a constituir uma identidade nacional, mesmo com tanta diversidade étnica, racial, religiosa, de classe e gênero (HALL,

4 Conversando recentemente com um islandês que mora no Brasil há cinco anos, quando disse que era capoeirista imediatamente ele me disse: "acho muito interessante a capoeira, essa luta dos escravos negros."

5 Chauí (1984) destaca esse processo de assimilação e domesticação da cultura popular no Brasil pelas classes dominantes que a retiram de suas ligações com os grupos específicos de produção e consumo e a tornam produto e produção nacional: a feijoada, o samba e as religiões afro-descendentes.

6 Meu nome foi dado em homenagem ao famoso romance de Jorge Amado, Gabriela, cravo e canela. Certa vez, quando da visita a uma Bienal de livros em São Paulo, meu pai viu Jorge Amado e levou o romance para que ele autografasse para mim. Ele então assim escreveu: "Do pai da Gabriela de Ilhéus, para o pai da Gabriela de São Paulo".

7 Curiosamente, Jorge Amado foi dos intelectuais mais importantes na constituição da capoeira da Bahia, especialmente a capoeira angola, como símbolo da cultura nacional. (PIRES, 2010). 
2014). Assim, as culturas nacionais são ficções narrativas $^{8}$ que convocam imagens, representações e práticas capazes de conectar o passado e o presente, apaziguando o conflito, as diferenças e as desigualdades, como forma de construir pela imaginação uma unidade nacional ${ }^{9}$, que mais que territorial e linguística, é, sobretudo, uma unidade identitária (ANDERSON, 1991; HALL, 2014).

[...] a nação não é apenas uma entidade política, mas algo que produz sentidos - um sistema de representação cultural. As pessoas não são apenas cidadãos legais de uma nação elas participam da idéia da nação tal como representada em sua cultura nacional (HALL, 2014, p. 30).

É por meio do jogo entre a fixação de certas memórias e o esquecimento quanto a certos acontecimentos marcados pela violência que essas narrativas são construídas. Ao situar no passado e na memória as batalhas e acontecimentos conflituosos, o discurso sobre a identidade nacional os torna como que origens míticas de guerras 'irmãos', isto é, membros de uma mesma família agora, a nação. (ANDERSON, 1991). Lembrar para esquecer, eis o sentido dessas diversas narrativas mais ou menos oficiais, presentes na literatura, mídia e no modo como a cultura popular pode ser recriada e reinventada com o intuito de agregar no imaginário as diferenças regionais, territoriais, sociais, raciais, culturais e, sobretudo, econômicas e políticas no território considerado nacional.

Os eventos reconstruídos pela narrativa nacional, ao funcionarem no registro do esquecimento de seus contextos originais, ressignificam memórias de conflitos entre posições de grupos diferentes, reinventando tradições atemporais à nação. Inúmeras narrativas nacionais funcionam sob essa lógica. Não por acaso Hall nomeia as narrativas nacionais como 'dispositivos discursivos de identidade’ em que as diferenças e identidades culturais parecem apagadas, desmanchadas e aparentemente resolvidas. (HALL, 2014).

Usando os termos de Althusser apenas no sentido descritivo, os aparelhos ideológicos do Estado bem como os repressivos são os lugares e instituições que condensam e centralizam a construção de hegemonia em torno dos discursos de identidade e cultura nacional. Para Gramsci, essa hegemonia exercida em última instância pelo Estado deve se valer de um sistema de alianças entre classes obtidas tanto por consentimento como por coerção. Nessa hegemonia operada pelas mãos do Estado, tanto as instituições produtoras da cultura erudita e universitária como as produtoras da cultura de massa, constroem diferentes estratégias de relacionamento com as culturas populares como forma de construção da identidade nacional (HALL, 2013).

Sendo assim, convém lembrar que discursos de identidade estão a serviço dos interesses do capital que necessita uniformizar os hábitos, costumes, os modos de viver, agir e pensar, procurando por meio do Estado a construção de hegemonia entre os blocos político-econômico e cultural por ele representado e os que ele exclusivamente governa, especialmente, as classes populares. Nesse sentido, a história das culturas populares só pode ser pensada na relação de conflito com as instituições de produção cultural dominante e nunca de modo autônomo e independente, fechadas em si mesmas (CHAUI, 1984; HALL, 2013).

\section{Culturas Brasileiras: a Dinâmica entre a Cultura Popular e a Cultura Dominante}

Se as reflexões sobre cultura e identidade nacional apontaram para a produção de uma narrativa que se pretende unificadora das diferenças culturais existentes no território nacional, parece importante

8 Por ficções narrativas entendo o campo de discursos e evidentemente, práticas que reinventam tradições com o intuito de consolidação e unificação tanto imaginária como simbólica sobre a base real de um território nacional (CHAUI, 1984).

9 Segundo Anderson (1991, p. 32), "ela é imaginada porque mesmo os membros da mais minúscula das nações jamais conhecerão, encontrarão, ou sequer ouvirão falar da maioria de seus companheiros, embora todos tenham em mente a imagem viva da comunhão entre eles." 
situar o campo de tensão estabelecido com as culturas dominantes. Para tanto, parece prudente perceber as formas como a cultura popular pode ser definida em situação e relacionamento às culturas dominantes e às instituições que as produzem e reproduzem, bem como sua capacidade de resistir e conformarse. As concepções acerca do campo de tensão entre a cultura popular e as culturas dominantes pedem o exercício da colaboração dos autores no sentido de explicitar aspectos novos sobre as relações entre cultura popular e as culturas ditas dominantes mais do que propriamente a disputa ou a distinção de suas perspectivas. Para tanto, retomo alguns aspectos trazidos pelas concepções de Bosi (1992), Chaui (1984), Hall (2013) e Certeau (2014) que serão aproveitadas em suas semelhanças e diferenças para fazer pensar o campo das tensões e ambiguidades enfrentadas pela e na capoeira entendida como cultura popular.

Em a Dialética da Colonização, Bosi (1992) já havia desconstruído a ideia de unidade de identidade e cultura nacional, nomeando a pluralidade de culturas brasileiras, ou melhor, culturas que acontecem simultaneamente no território nacional.

A identidade possível entre essas culturas como brasileiras refere-se unicamente ao fato de se realizarem no território político que define a nação. Fora isso, a diversidade cultural brasileira foi reconhecida e nomeada por diferentes critérios: raciais, étnicos, regionais e de classe.

Para Bosi (1992), a cultura popular pode ser entendida como a cultura produzida e consumida por grupos e comunidades que não detém o poder nem sobre o conhecimento e produção cultural nas universidades, nem tampouco sobre a indústria cultural. ${ }^{10}$ Para ele, o termo popular reúne uma série de culturas minoritárias ligadas a grupos étnicos e raciais, regionais, religiosos, gente do campo ou da cidade que persistem produzindo e consumindo modos de viver, hábitos, objetos, tradições, festas e ritos simbólicos próprios que expressam suas formas de levar a vida cotidiana bem como de compreender e organizar os grandes temas humanos.

No que se refere ao relacionamento entre cultura popular e cultura de massa, sabe-se o quanto persiste a vampirização da cultura popular pela cultura de massa, que explora os objetos, festas e ritos da cultura popular como novos objetos de consumo, devolvendo-os de modo simplificado e pasteurizado para que sejam novamente consumidos. Como não pensar nos berimbaus e caxixis, e na própria roda de capoeira, sendo vendidos em inúmeras feiras e mercados de artesanato popular como souvenir para turistas brasileiros e estrangeiros espalhados pelo território nacional?

A cultura popular costuma ser apropriada como símbolo da comunidade nacional e, em circunstâncias de aparição mais ou menos oficial, é frequente que tenha se tornado um espetáculo reificado e estereotipado, sem que qualquer enigma tenha sido preservado acerca de sua relação com o passado ou com o presente dos grupos tradicionais que a produziram como manifestação simbólica e expressiva do seu modo de organizar e pensar a vida. ${ }^{11}$ Pode se tornar folclore na sua tentativa de preservação museificada, pela operação de seu congelamento no tempo e no espaço e, sua separação dos usos e sentidos rituais e cotidianos nas comunidades populares. Mas, pode ser espetacularizada e reificada pelos grandes empreendimentos da indústria cultural como nas festas do Boi do Maranhão ou do Carnaval. Das duas formas, é o estado de inércia que esses objetos, ritos e práticas assumem quando possuem seu campo de sentidos e significações fixados. (BOSI, 2003) Mas Bosi (1992) insiste na dialética de forças

10 Para Bosi (1992), é possível reunir essas culturas em quatro categorias amplas que poderiam revelar interfaces da produção, reprodução e consumo cultural diferentes no território brasileiro. São elas: a cultura erudita e universitária, a cultura criadora individualizada, a cultura de massa e a cultura popular.

${ }^{11} \mathrm{O}$ folclore é justamente essa reificação da cultura popular, quando aparece destituída de seus sentidos na história, no cotidiano da vida de um grupo. 
que, simultaneamente, permitem a expropriação e cooptação da cultura popular, especialmente pela cultura de massa, e a constituição de formas de resistência que se esquivam e escapam a esse movimento a partir da ideia de reinterpretação.

Um grande antropólogo, Herskovits, insistiu nesse fenômeno da reinterpretação, pelo qual toda cultura dominante é absorvida e descodificada pela cultura dominada, de tal modo que, nesta última, já não fica da cultura superior nada a não ser, talvez, o desejo que têm os dominados de apreender os dons e os poderes dos seus patrões. A refacção do culto pelo iletrado é matéria permanentemente aberta aos estudiosos da cultura popular. (BOSI, 1992, p. x) ${ }^{11}$

Tanto Bosi (1992), Chauí (1984), Hall (2013) e Certeau (2014) apostam nessa resistência conquistada nos modos como fazem o uso e reinterpretam a cultura dominante.

Se, por um lado, há expropriação da cultura popular pela sua espetacularização forjada para grandes públicos, a cultura erudita ou universitária pode incorrer em formas bastante comuns de relacionamento: a invisibilidade e o desprestígio a que a cultura popular está sujeita como objeto de interesse na universidade e, por outro lado, diferentes formas de apreço e simpatia pela cultura popular que vão da exaltação demagógica populista, passando pelo etnocentrismo que considera ainda assim manifestações do espírito 'primitivo' e 'instintivo', inferior ao branco e, por último, na produção de obras de artes que se valem das formas de expressão e simbologia próprias da cultura popular para serem produzidas. ${ }^{12}$ Considero que essas formas de contato e relacionamento entre cultura popular e cultura erudita não são progressivas ou mutuamente excludentes, mas assinalam formas comuns e alternadas de relacionamento que podem se tornar mais ou menos preponderantes, mas que, sobretudo, apontam para a existência de tensionamentos e ambiguidades que não podem e nem devem ser resolvidas por novas formas de populismo que aplacam as diferenças entre classes.

A perspectiva de Bosi (1992) colabora para esclarecer o campo da cultura popular, explicitando que: a) cultura popular não se equivale à cultura de massa; b) que cultura popular relaciona-se de diversos modos com as instituições da cultura de massa e a cultura universitária; c) que o relacionamento não significa nem uma completa expropriação ou aculturação à cultura de massa, nem tampouco um isolamento, mas sim que a cultura popular reinterpreta ao seu modo os elementos postos pela cultura de massa; d) que tanto a cultura de massa como a cultura erudita ou universitária possuem instituições de onde produzem políticas culturais. Mas deixa a desejar no sentido de pensar e fazer a crítica à estreita relação política e econômica entre os produtores da cultura de massa e os produtores da cultura erudita como forças constituidoras da hegemonia cultural e, portanto, do Estado.

Nesse sentido, as contribuições de Chaui (1984) e Hall (2013) ao campo dos estudos culturais assemelham-se, pois procuram evidenciar a cultura popular como um pólo de ambiguidades e contradições com a cultura dominante, em que

12 Da mesma forma, Certeau retoma essas formas de resistência ao poder disciplinador operado pelas instituições coloniais. Diz ele: "Submetidos e mesmo consentindo na dominação, muitas vezes indígenas faziam das ações rituais, representações ou leis que lhes eram impostas outra coisa que não aquela que o conquistador julgava obter por elas. Os indígenas as subvertiam, não rejeitando-as diretamente ou modificando-as, mas pela sua maneira de usá-las para fins e em função de referências estranhas ao sistema do qual não podiam fugir." (CERTEAU, 2014, p. 39). Embora as análises de Certeau sejam profícuas em termos de dar visibilidade a pequenas ações de resistência postas pelo modo de apropriação no cotidiano da cultura dominante, ele não evidencia as ações diretas de resistência a dominação que não utilizavam apenas de táticas na apropriação, mas que se contrapuseram deliberadamente as ações de dominação, como as revoltas e guerras indígenas e dos negros escravizados, bem como dos trabalhadores.

${ }^{13}$ As obras artísticas, as teses e livros publicados que tematizam a cultura popular nessas diversas perspectivas muito frequentemente se restringem a serem consumidas pela própria universidade, poucas vezes encontrando formas de serem reaproveitadas pelos grupos populares. Frequentemente o são quando tomam como problemática política e ética a dimensão da produção de conhecimento no encontro entre o intelectual e os grupos populares, procurando devolver aos grupos populares o conhecimento gestado junto com eles (CLIFFORD, 1998; SCHIMDT, 2006). 
pouco sentido faz pensar em termos da separação entre cultura de massa e cultura universitária, uma vez que, frequentemente, se reúnem em termos de classes, instituições e políticas culturais hegemônicas. A cultura é campo em que se dá a luta de classes, uma vez que persiste a luta política e cultural pela hegemonia de discursos que de modo indireto e mediado organizam as relações de produção e consumo na sociedade de classes.

Para Chauí (1984, p. 33), há uma diferença de natureza entre a cultura popular e a cultura de massa que pode ser compreendida como: "um conjunto disperso de práticas dotadas de lógica própria, mas uma lógica que se constitui durante os acontecimentos, durante a ação, definida local e temporalmente por seus sujeitos", ao passo que a cultura de massa operaria uma lógica de uma "estrutura totalizante dotada de referenciais e de regras anteriores à prática da comunicação.”

A cultura popular entraria nesse campo de luta contra hegemônica, mas que, por ainda acontecer sob o regime da dominação, carrega aspectos da ambiguidade de movimento de resistência e, ao mesmo tempo, de conformismo (CHAUI, 1984).

Ainda que concordem com a ambiguidade própria à cultura popular que caminha entre o conformismo e a resistência para Chauí, ou entre a resistência e o consentimento para Hall, é possível notar uma separação quanto à definição do que seja o popular. Para Hall (2013), o atestado do que seja popular ou não, isto é, da linha divisória entre o que é do povo ou não, não é dado por significações essencializadas quanto às manifestações, costumes, expressões, hábitos, ritos, ou seja, os diversos conteúdos e formas culturais históricas que nasceram, em certo momento histórico, com as classes populares. Segundo ele, a definição deve ser pensada entre "aquilo que pertence ao domínio central da elite ou da cultura dominante, e a cultura da 'periferia'."
(HALL, 2013, p. 284). Ao funcionar por essa lógica e não pela descrição isolada dos elementos culturais, coloca-se em jogo a dialética operada pelas forças e relações culturais. Um exemplo desse jogo em que hábitos, manifestações, mentalidades, isto é, "coisas que o povo fez e faz", podem ser esvaziadas do sentido original é o prato da culinária brasileira: a feijoada. De um prato típico da cultura popular negra, ligado à violência e espoliação econômica, tornou-se amplamente reconhecido como um prato tipicamente brasileiro, consumido em todo território nacional tanto pelos populares como pelas elites. (CHAUÍ, 1984; FLY, 2005). O que se quer dizer é que as práticas e lógicas de resistência podem ser esvaziadas de sua significação original e cooptadas pelo discurso hegemônico, sendo veiculadas por instituições que comandam a política cultural.

Nesse sentido, duas ideias são importantes a serem destacadas em Hall (2013, p. 284): a definição do que seja cultura popular como "as formas e atividades cujas raízes se situam nas condições sociais e materiais específicas, que estiveram incorporadas nas tradições e práticas populares" e o fato de que essas formas e atividades devem ser pensadas dentro do processo histórico em que ocorre o jogo e a luta das relações culturais. Um terceiro elemento é fundamental para esclarecer a noção do que seja popular. Para Hall (2013, p. 290), o termo popular não se refere exclusivamente a uma única classe, a dos trabalhadores, por exemplo, mas uma aliança entre classes e forças que a constituem como cultura dos excluídos da produção de política cultural. ${ }^{14}$

Assim, há que se pensar na capoeira como cultura popular nos sentidos constituídos por essa nova hegemonia formada nas décadas de 30 e 40, seus efeitos sobre a capoeira nos anos seguintes, em que a capoeira e outras manifestações culturais negras passam a ser valorizadas e apropriadas pelo discurso da identidade nacional, pelo menos em dois projetos: seja como esporte ou ginástica

\footnotetext{
${ }_{14}$ Para Hall (2013, p. 290), "o lado do poder de decidir o que pertence e o que não pertence - não é, por definição, outra classe inteira, mas aquela outra aliança de classes, estratos e forças sociais que constituem o que não é "o povo" ou as "classes populares": a cultura do bloco do poder.
} 
nacional seja como cultura afro-brasileira, tendo sido retirada de sua prática os aspectos belicosos e próprios da violência.

\section{A Construção da Identidade e Cultura Brasileira}

Segundo Munanga (1996) as questões relativas à formação da identidade e cultura nacional afloraram em três principais momentos: por circunstância da independência do país da coroa portuguesa, em 1822; em 1888 e 1889, por ocasião da abolição da escravatura e o surgimento da República e, por fim, na revolução de $1930 .{ }^{15}$ Nesse momento inicial da Primeira República, vários intelectuais tomavam o termo raça como elemento definidor e constituidor da identidade nacional.

As narrativas de constituição da identidade e cultura nacional que passam a operar, especialmente, na Primeira República, por ocasião do fim da escravidão, devem dar conta de articular dois problemas: a diversidade racial e a diversidade étnica ou cultural, consideradas fatores negativos à formação do Estado Nacional (MUNANGA, 1996).

Muitos intelectuais brasileiros incorporavam as teorias do determinismo biológico importadas que apontavam para a degeneração física e moral da raça negra e tanto mais dos mestiços. Por outro lado, chocavam-se com a existência de uma sociedade brasileira composta por pretos e mestiços, dificultando as reflexões acerca da possibilidade de construção de identidade nacional. Diante das circunstâncias históricas e da produção intelectual brasileira e internacional estava muito presente o apreço pelas teorias raciais e, consequentemente, por visões eugenistas que apontavam para complexidade de se pensar a nação (MUNANGA, 1996; ORTIZ, 2003).

Entre as explicações racistas, as teses poligenistas de Gobineau pressupunham que as raças não possuíam a mesma gênese. O cruzamento inter-racial, portanto, significaria a perda da raça branca e superior e a produção de seres inférteis e incapazes, os mestiços que comprometeriam o potencial civilizatório do país. O mulato, nome dado, ao mestiço do branco e negro, provém de mula, animal híbrido e infértil, resultado da mistura entre o jumento e a égua. (CARONE; BENTO, 2002)

Dentre os críticos da mestiçagem, Nina Rodrigues acreditava "na inferioridade do negro e na degenerescência do mestiço", não vendo na miscigenação possibilidade do país alcançar uma saída para a constituição da identidade nacional, seja do ponto-de-vista étnico, seja racial (MUNANGA, 1996)

As vertentes evolucionistas e darwinistas se articularam no país de um modo próprio, visando à possibilidade de pensar e existir uma nação que já sofria do mal da miscigenação, a partir de políticas diversas de branqueamento - políticas de imigração de europeus e orientais, políticas de incentivo a casamentos inter-raciais e repressão à cultura popular. Note-se que o problema não era apenas da miscigenação racial, isto é, o cruzamento das raças, mas, como lembrado por Munanga (1996), a miscigenação cultural. Por isso, a extensa perseguição às culturas negras e a necessidade simultânea e semelhante de que essa fosse branqueada.

15 Chauí (1984, p. 99-100) faz um interessante percurso sobre as formas como o Estado Brasileiro se relacionou com a cultura popular para a construção da identidade e cultura nacionais até a década de 80 . "durante os anos 10 , o slogan dominante era Consolidar a Nação (o que legitimou o extermínio dos rebeldes de Canudos e Contestado); durante os anos 20 e 30: construir a nação (o que permitiu a absorção de todas as manifestações culturais pelo Estado); durante os anos 40 e 50: desenvolver a Nação (fazendo com que a Cultura Popular fosse considerada atraso, ignorância e folclore); no início dos anos 60: Conscientizar a Nação (levando o populismo a produzir a imagem dupla da Cultura Popular como boa-em-si e alienada-em-si, precisando da condução de vanguardas tutelares e revolucionárias); durante os anos 60 e 70: Proteger e Integrar a nação (o que levou às práticas modernas de controle estatal da Cultura Popular); e agora: Conciliar a Nação (o que talvez seja feito num grande festim onde comeremos broa de milho). 
Segundo Schwarz (2012, p. 39):

[... fazendo-se um casamento entre o modelos evolucionistas (que acreditavam que a humanidade passava por etapas diferentes de desenvolvimento) e darwinismo social (que negava qualquer futuro na miscigenação racial) arranjo esse que, em outros contextos, acabaria em separação litigiosa -, no Brasil as teorias ajudaram a explicar a desigualdade como inferioridade, mas também apostaram em uma miscigenação positiva, contanto que o resultado fosse cada vez mais branco.

Essa mesma discussão comparece entre intelectuais que na Primeira República vão pensar nas formas de apropriação da capoeira. Durante o Império, era praticada por negros escravizados, libertos e livres, prioritariamente ${ }^{16}$, tendo sido extremamente perseguida e considerada contravenção penal (REIS, 2000). Na primeira metade do século XIX, os capoeiristas eram em sua maioria negros escravizados que iam presos por sua prática; na segunda metade, em função do próprio processo de proibição do tráfico negreiro e das consequentes leis de ventre livre e do sexagenário, negros escravizados, libertos e livres praticavama capoeirano Rio de Janeiro, sendo presos seja por "promover desordens que levariam a perturbação da ordem pública" (portaria 0446, 30 de agosto de 1824), seja por "andar armado" (portaria 0551, 17 de abril de 1834) e ferir pessoas (REIS, 2000, p. 25). As penas variavam entre o açoite e o trabalho compulsório para o governo, ou prisão, o que significava grande prejuízo para os senhores proprietários de negros escravizados. Mesmo sendo perseguidos e punidos, havia uma rede de relações importantes entre capoeiras e o Estado na segunda metade do século XIX, na capangagem eleitoral e nas guardas de defesa do território nacional, em troca de pequenos favores e benefícios (VASSALO, 2003).

Contudo, após a abolição da escravidão, durante a Primeira República, é que a capoeira foi criminalizada no Código Penal e que se iniciam as primeiras tentativas, nascidas entre intelectuais das classes dominantes, de fazer dela esporte ou ginástica nacional, destituindo-a de sua origem negra escravizada, e reinventando uma origem mestiça e autenticamente brasileira (PIRES, 2010; REIS, 2000). Assim, a capoeira, como cultura popular negra, encontrou duas formas de relacionamento no Estado: seus praticantes, negros e mestiços, foram duramente perseguidos e reprimidos pelo Estado, porém sua prática corporal, sua 'ginástica', quando 'purificada' dos seus elementos étnicos e raciais, será vista como de grande valor para a formação de identidade nacional. Coelho Neto, Mello Moraes Filho, Aníbal Burlamarqui e Inezil Penna Marinho, em diferentes períodos e com algumas diferenças, consideravam a capoeira como uma excelente prática corporal que deveria ser incorporada pelo Estado e reconhecida em seu valor nos projetos higienistas de educação física nas escolas e nos exércitos. Para torná-la apropriável como ginástica nacional, era necessário que a capoeira eliminasse seus elementos ligados aos seus grupos étnicos e raciais, realizando um branqueamento. Os muitos aspectos que denotavam a sua pertença racial e étnica foram negados ou não eram citados: a ausência de comentários acerca da musicalidade, o caráter meramente esportivo que se sobrepunha aos aspectos ambíguos da manifestação popular em que os elementos de luta-dança-jogo não estavam separados, ou mesmo, a clara tentativa de afirmar que a capoeira deveria ser praticada pelo mestiço (PIRES, 2010; REIS, 2000).

\begin{abstract}
Os mulatos, geralmente menos corpulentos que os negros, menos sobrecarregados de músculos de força que o trabalho pesado desenvolvia, mais agéis, mais flexíveis, mais elásticos, mais nervos do que músculos, representavam o tipo ideal de capoeira, pois a tais qualidades físicas somavam maior coragem, maior audácia, libertos que se encontravam do espírito de submissão arraigado à raça negra, pelo menos naquela época (MARINHO, 1945, p. 7 apud REIS, 2000, p. 85-86).
\end{abstract}

Enquanto alguns intelectuais procuravam tornar a capoeira uma "arte marcial genuinamente brasileira" ou "esporte ou ginástica nacional",

\footnotetext{
${ }^{16}$ Embora também tenha contado com a participação ainda diminuta de brancos imigrantes, principalmente, portugueses. (REIS, 2000).
} 
produzindo um branqueamento, outros foram capazes de construir uma nova hegemonia, aliando diversas classes sociais, ao valorizarem os elementos étnico-raciais na construção da identidade nacional. Entretanto, é possível reconhecer nos discursos e práticas da capoeira a presença dos dois projetos ainda presentes até os dias de hoje.

\section{Novas Hegemonias: o Mito da Democracia Racial Brasileira e a Capoeira}

$\mathrm{Na}$ década de 30 , esse processo da construção do imaginário nacional brasileiro na Primeira República encontrou um caminho e saída possível para o desenvolvimento nacional, às voltas com interpretações dadas pelas teorias raciais sobre a formação do povo brasileiro e, consequentemente, sobre a sua cultura, deslocando o centro da discussão de raça para cultura (ORTIZ, 2003) A versão culturalista construída por Gilberto Freyre valorizava no país as formas de miscigenação tanto cultural como biológica entre as três raças que formavam a nação: o índio, o branco e o negro. Isto foi o que se convencionou a chamar de democracia racial brasileira constituída pela idéia de uma nação receptiva a todos, afetuosa e pacífica, capaz de ensinar aos outros países como as diferenças raciais e étnicas conviviam de modo harmônico nesse território, até porque nossa formação era marcada pela mestiçagem (MUNANGA, 1996; SCHWARCZ, 2012).

Freyre propunha uma nova forma de ver a história nefasta da escravidão brasileira, valorizando-a e apontando a convivência afetuosa entre negros escravizados e senhores do engenho nordestino. O mito da escravidão boa e gentil, do escravizado generoso, servil e dócil, do senhor branco cordial, da afetividade e amizade do povo brasileiro incapaz de reconhecer distinções de classe e raça alimentaram e ainda alimentam a imaginação brasileira e os discursos sociais (SCHWARCZ, 2012).
O mito da democracia racial, baseado na dupla mestiçagem biológica e cultural entre as três raças originárias, tem uma penetração muito profunda na sociedade brasileira: ele exalta a ideia de convivência harmoniosa entre os indivíduos de todas as camadas sociais e grupos étnicos, permitindo às elites dominantes dissimular as desigualdades e impedindo os membros das comunidades não-brancas de terem consciência dos sutis mecanismos de exclusão da qual são vítimas na sociedade (MUNANGA, 1996).

Certamente serviu para a construção desse imaginário nacional a valorização de uma região brasileira e de seus hábitos de convivência cordial, como construídos por Freyre e endossado por outros intelectuais na imagem do senhor de engenho generoso do Nordeste (SCHWARCZ, 2012). O foco de interesse de intelectuais e do Estado migrou para a supervalorização de manifestações culturais negras no Nordeste, classificando as manifestações por critérios de pureza e degradação (DANTAS, 1982). Para Dantas, há uma composição na democracia racial brasileira entre a mistura como formação racial do país e a valorização em termos diacríticos de um passado em que as tradições culturais de cada povo eram mais puras e preservadas. Tratava-se de salvar e dar conhecimento a um Brasil antigo, rural que mantinha em seus hábitos e manifestações culturais a integridade nacional, livre dos efeitos danosos e mesquinhos da modernidade. ${ }^{17}$

Não por acaso, é a partir da década de 30, do século XX, que saindo do código penal a capoeira baiana junto com outras manifestações culturais negras foram incorporadas ao Estado. O conceito de hegemonia criado por Gramsci oferece a novidade ao reunir a ideia de cultura como prática social que carrega uma visão de mundo ao conceito de ideologia.

A hegemonia é uma práxis e um processo, pois se altera todas as vezes que as condições históricas se transformam, alteração indispensável para que a dominação seja mantida. [...]. Deve ser continuamente renovada, recriada, defendida e modificada e é continuamente resistida, limitada, alterada, desafiada

${ }^{17}$ Vassalo (2003) vê aí o interesse em inventar a origem da capoeira na Bahia. 
por pressões que não são suas. Nesse sentido, devemos acrescentar ao conceito de hegemonia os conceitos de contra-hegemonia e hegemonia alternativa, que são elementos reais e persistentes da prática. (CHAUI, 1984, p. 22).

A construção dessa nova hegemonia, isto é, um arranjo político e cultural entre diversas classes, comandado por forças do Estado, valorizavam e legitimavam a existência da cultura popular negra, como parte do cultura ou folclore nacional (DANTAS, 1982; PIRES, 2001; REIS, 2000, 2004; VASSALO, 2003). Nesse ponto, é importante dizer que dois projetos de capoeira reinventaram e disputaram entre si o lugar de aceitação e afirmação da capoeira na década de 30 e, sobretudo, 40, na Bahia: a Capoeira Angola, de Mestre Pastinha e a Luta Regional Baiana, de Mestre Bimba. ${ }^{18}$ Com algumas diferenças, os dois projetos se aliaram a grupos políticos e intelectuais diversos, porém tinham em comum a ideia de que a capoeira pudesse ser amplamente divulgada e aceita como prática esportiva nacional (PIRES, 2001).

Tanto a Capoeira Angola como a Capoeira Regional significaram uma profunda ruptura com a capoeira do século XIX e início do século XX, e a reinvenção de uma capoeira longe das ruas e purificada dos elementos que podiam imediatamente marginalizá-la, como as maltas e malandros, tanto no Rio de Janeiro como na Bahia. Daí o sentido de aliá-la ao esporte ou a luta, em Mestre Pastinha e Mestre Bimba, sem que perdesse seus elementos lúdicos e ambíguos, por assim dizer (PIRES, 2001).

Sob o contexto de repressão da capoeira vivido nas primeiras décadas do século XX, mestres Bimba e Pastinha procuraram retirá-la das ruas praticada por trabalhadores e 'malandros' e levála para a academia. A capoeira tanto Angola como Regional passou a ser praticada por pessoas de diversas classes sociais e não negros ${ }^{19}$, (estudantes, políticos e intelectuais) ganhou espaços institucionalizados para sua prática em academias oficiais tanto de Mestre Bimba e Mestre Pastinha, e institucionalidade e legitimidade em espaços oficiais do Estado (apresentações artísticas, circuito turístico e participação em campeonatos e lutas de ringue, especialmente a Capoeira Regional, que incialmente separava os momentos de prática artística e lúdica da prática meramente esportiva ou marcial em campeonatos) (PIRES, 2001; REIS, 2004).

\begin{abstract}
Desse modo, eles brigavam principalmente por espaços, nesse caso para comercializar a capoeira, pelo status social no grupo e pela manutenção das relações com diversos agentes de poder. Mestre Bimba e mestre Pastinha também brigaram pelos espaços culturais, políticos e econômicos da sociedade. O comércio da capoeira tornou-se um fato fundamental. A retirada da capoeira do código penal de 1890 foi uma tarefa que significou, fundamentalmente, colocala no âmbito das relações fundamentais do sistema capitalista, o que resultou na criação de academias de capoeira. Assim os agentes produziram outra forma de comercializar a cultura, tentando fugir das práticas criminais (PIRES, 2001, p. 303-304).
\end{abstract}

Assim, parece que tanto um discurso como outro, isto é, tanto o discurso em que a capoeira era veiculada como Luta Regional Baiana, luta dos negros africanos que nasce nas senzalas do Recôncavo Baiano, como pela via do discurso da africanização da Capoeira Angola, como herança original e pura africana, a capoeira conquistou seu espaço na cultura nacional. Essa negociação e consentimento com a cultura dominante encontrava apoio no discurso hegemônico que positivava e valorizava a presença e a preservação dos traços étnicos e raciais, exigindo que fossem

\footnotetext{
${ }^{18}$ A distinção das duas capoeiras, Angola e Regional, levou a várias disputas e rupturas entre os próprios capoeiristas pela capoeira mais legítima ou mais eficiente, aumentando em parte a violência entre os praticantes (PIRES, 2001; REIS, 2000).

${ }^{19}$ Chama a atenção a análise feita por Pires (2001) acerca da mudança do perfil racial dos alunos de Mestre Bimba que frequentavam a Roça do Lobo, em 1918, espécie de terreiro no fundo da casa, na periferia do bairro de classe média em Salvador, para posteriormente, sua academia no Clube de União em Apuros, em 1930. Se num primeiro momento a maioria é formada por negros, já, em 1930, nota-se a presença da maioria de alunos brancos e de classe média, apontando para o fato da integração das classes médias e altas na prática da cultura popular.
} 
controlados e purificados dos elementos de desordem e marginalidade impostos pelas relações conflituosas entre classes e raças no ambiente das cidades. Não por acaso os elementos da violência, da malandragem e da organização em maltas são subtraídos da imagem da capoeira ${ }^{20}$.

A obra de Freyre sinaliza para o acordo cordial tanto do ponto de vista cultural como biológico entre brancos e negros. Ao lado dele, outros intelectuais passaram a organizar os Congressos Afro-Brasileiros ${ }^{21}$, apropriando-se dos símbolos da cultura africana para a construção de uma nova hegemonia nacional. As manifestações culturais e religiosas negras, como o candomblé ketu, a capoeira de angola, o samba e as comidas típicas do povo negro foram amplamente divulgadas e valorizadas (PIRES, 2001; VASSALO, 2003).

Não é o intuito desse trabalho discutir a respeito das táticas e estratégias (CERTEAU, 2014) usadas por cada um dos mestres e dos grupos políticos a eles associados para efetivar essa tarefa, se pela via da africanização da origem da capoeira, como na Capoeira Angola de Mestre Pastinha, ou pela via da regionalização da capoeira como luta do escravizado na Bahia, como na Capoeira Regional (Luta Regional Baiana) (REIS, 2000, 2004). Até porque, e nesse ponto, concordo com a interpretação de Pires, é necessário relativizar a disputa entre as duas capoeiras baianas, a Capoeira Angola e a Capoeira Regional, e problematizar outros projetos de capoeira que se opunham e se opõem de modo mais acentuado em relação ao elemento étnicoracial (PIRES, 2001, 2010).

Segundo Pires, os dois projetos ligados às instituições do Estado que transformaram a capoeira da prática popular à manifestação cultural nacional persistem e encontram terreno fértil até hoje no Brasil.
De modo geral, esses dois grupos acabaram por estabelecer conceitos fundamentais no pensamento social brasileiro, em virtude de suas análises acerca da cultura. $\mathrm{O}$ arcabouço teórico das obras surge a partir das noções de raça e nacionalidade. Obviamente, os grupos partiram das mesmas bases conceituais. Contudo, utilizaram táticas diferentes para alcançarem seus objetivos que, de forma geral, culminavam com a formação de uma cultura nacional. Essa cultura deveria se constituir a partir da justaposição das culturas brancas, negras e indígenas. As divergências entre esses intelectuais estão colocadas em um plano superficial em relação à idéia de cultura nacional, mas que, profundamente, revelam a complexidade da manipulação, por parte deles, das categorias de raça e cor na construção dessa nacionalidade. A visão folclórica, a valorização da África, e a busca da cultura negra demarcaram uma posição; já o nacionalismo exacerbado, a esportividade e a mestiçagem cultural demarcaram outra (PIRES, 2010, p. 4-5).

Tanto o projeto nacionalista e mestiço, presente nas diversas discussões que esbarram na esportização da capoeira e na transformação em luta olímpica até um projeto que a legitimava como cultura negra seja pela via da Capoeira Angola (étnica e racialmente), seja pela via da Capoeira Regional (no regionalismo baiano) permanecem presentes, disputando o mercado nacional e internacional da capoeira.

Ora, percebe-se deste modo que, desde suas origens, a capoeira como manifestação cultural popular ligada racial e etnicamente aos negros não pode existir em separado, fora do campo de luta e resistência travado com as instituições do Estado escravista e, posteriormente, com o Estado pós-escravista, que deve dar conta de exercer diferentes estratégias de poder sobre as comunidades populares negras. Assim, não há como pensar a capoeira, bem como qualquer outra cultura popular, sem acionar a tensão contínua, de relacionamento, influência e antagonismo com a cultura dominante operada pelo Estado e seus blocos de aliança (HALL, 2013).

${ }^{20}$ Dantas (1982) aponta para o fato de que a construção dessa nova hegemonia em torno da valorização da cultura africana foi a maneira negociada pelo Estado de garantir um controle sobre as comunidades negras diante da extrema desigualdade social, econômica e política, especialmente, presentes no Nordeste.

${ }^{21}$ O I Congresso Afro-Brasileiro aconteceu em 1934, em Recife; O II Congresso Afro-Brasileiro aconteceu em Salvador, em 1937, organizado por Edson Carneiro e Jorge Amado (PIRES, 2001). 


\section{Entre a Ideologia e a Utopia: a Democracia Racial Brasileira}

Entretanto, desde quando a UNESCO encomendou a pesquisa para a Escola Paulista de Sociologia, em 1950, como forma de estudar e apreender as formas 'positivas' e 'acertadas' de convivência inter-racial no Brasil, esse discurso sofreu duras críticas. A miscigenação cultural e biológica mistificadas pela democracia racial brasileira foi questionada pelas observações e dados empíricos sobre a posição de pretos e mestiços na estrutura social, política e econômica do Brasil. (MUNANGA, 1996). Nesse processo, tornouse evidente pelos dados sociais, econômicos e políticos a demarcação de uma desigualdade racial bem visível (SCHWARZ, 2012).

As lutas do movimento negro bem como de intelectuais engajados com a questão racial apontaram que o racismo no Brasil, diferente daquele vivido em outros países, é um racismo de marca ou de cor, isto é, que considera o fenótipo (cor da pele e traços físicos) e não a origem na classificação da cor e na distribuição de privilégios materiais e simbólicos. No mais, o racismo brasileiro não é uma política do Estado, constituído por leis segregacionistas, mas um racismo da intimidade (CARONE; BENTO, 2002; SCHWARCZ, 2012; SOVIK, 2009).

Em outros países, como nos Estados Unidos e África do Sul, pelo contrário, é a regra quanto à origem negra, one drop role, que determina a identidade e classificação racial, uma vez que o racismo foi uma política do Estado segregacionista. Além dela, outro critério é fundamental para a constituição das identidades étnico-raciais miscigenadas: a filiação dos indivíduos miscigenados ao grupo racial considerado inferior, a hipodescendência (MUNANGA, 1996). Ao contrário da perspectiva de constituição das narrativas ficcionais forjadas pelo Estado brasileiro, esses países não integraram nem racialmente, nem culturalmente os negros; não por acaso, a feijoada, conhecida como soul food nos Estados Unidos, permanece sendo uma comida tipicamente dos negros (FRY, 2005).

A existência do preconceito racial e os efeitos nas desigualdades e injustiças enfrentadas pela população negra nos mais diversos setores educação, saúde, trabalho, renda, lazer e até mesmo matrimônio em relação à população branca - apontaram e persistem apontando para o caráter ideológico da democracia racial e para a existência de uma hierarquia racial que dita o acesso a bens materiais e simbólicos.

No entanto, a despeito das evidências reais e cotidianas, o mito da democracia racial foi amplamente internalizado na população brasileira de modo a funcionar como uma forma de pensamento próprio da vida cotidiana resistente às provas de realidade (HELLER, 2004). Aqui, por exemplo, acredita-se que o racismo seria mais brando, integracionista, em detrimento de outros, segregacionistas (SCHWARZ, 2012).

\footnotetext{
Ora, a raça no Brasil sempre foi um tema discutido 'entre pessoas' e fora do estatuto da lei: uma questão privada, mas que interfere, amplamente, na ordem pública. Nessa sociedade marcada pela desigualdade e pelos privilégios, "a raça" fez e faz parte de uma agenda nacional pautada por duas atitudes paralelas e simétricas: a exclusão social e a assimilação cultural. Apesar de grande parte da população permanecer alijada da cidadania, a convivência racial é paradoxalmente, inflacionada sob o signo da cultura e cada vez mais reconhecida como um ícone nacional (SCHWARZ, 2012, p. 115).
}

No entanto, é preciso pensar que se não há reconhecimento público do racismo, e se o racismo é algo do outro e na intimidade, é como se o racismo não tivesse lugar de existência para ser pensado largamente, sem que com isso viesse à tona tensões e desconfortos ligados evidentemente ao sentimento persecutório de auto/alo-acusação, seguidos de vergonha e culpa; nem praticantes nem alvos de racismo querem ser reconhecidos (BENTO; CARONE, 2002). Por outro lado, qualquer discussão acerca das desigualdades raciais serviria para abalar a forma amistosa e integracionista com que negros 
e brancos convivem em território nacional, podendo acirrar disputas e guerras étnicas e raciais, levando a formas segregacionistas de Estado, como nos Estados Unidos e África do Sul. ${ }^{22}$ (FRY, 2005).

No discurso proferido pelo Ministro Interino da Cultura, Juca Ferreira, por ocasião de ter sido a capoeira reconhecida como Patrimônio Cultural Brasileiro, ele diz:

Hoje tenho certeza que estamos vivendo um momento histórico nesse processo de valorização da Capoeira [...] O significado maior desse dia não beneficia apenas a Capoeira, mas beneficia a todos nós, beneficia o Brasil.

\section{$[\ldots]$}

Amanhã nosso país vai acordar mais generoso, mais próximo de si mesmo, um pouquinho mais perto da nossa grande utopia da democracia racial" (FUNDAÇÃO CULTURAL PALMARES, 2016).

Referindo-se ao mito da democracia racial brasileira, Juca Ferreira, ao mesmo tempo, que o critica, apontando para o seu caráter ideológico, e, portanto, apenas pressuposto na realidade, conserva a força da sua representação no presente e no futuro, como utopia a ser alcançada. $O$ fato de que a capoeira tenha se tornado Patrimônio Histórico Nacional é sinal de que o desencontro entre o mito e a realidade, cujo cotidiano difere bastante do plano da representação de democracia racial, esteja sendo ajustado. Não por acaso a capoeira ao receber o reconhecimento do Estado Brasileiro em sua política pública cultural, parece receber uma reparação pelos anos de indiferença, miséria, esquecimento e injustiça a que estão associados, de modo geral, seus mestres e praticantes bem como metonimicamente os cidadãos negros desse país.

O fato de o mito ter sido desmentido não impede que ele continue produzindo seus efeitos na realidade a tal ponto de ser retomado pelos discursos oficiais como forma de declarar: 'naquela época a democracia racial era mito, hoje em dia ela está no caminho correto para se tornar realidade.' Curiosamente, é pela ação política sobre os objetos culturais tipicamente de origem negra que o ajuste dessa engrenagem entre utopia e realidade, é novamente fomentado.

Contudo, não apenas na mídia ou entre representantes do poder do Estado, a democracia racial brasileira foi incorporada imaginariamente pelo brasileiro como a narrativa capaz de simultaneamente silenciar os problemas e conflitos internos advindos da violência histórica contra negros e indígenas, construindo uma imagem nossa para nós e para eles, entendidos aqui como as outras nações, como povo em que a mestiçagem deu certo ${ }^{23}$ (SOVIK, 2009; SCHWARCZ, 2012).

\section{A Capoeira e o Mito da Democracia Racial Brasileira}

Se a capoeira foi reinventada como para se adequar a uma importante narrativa nacional, o mito da democracia racial brasileira e sua valorização das manifestações negras tradicionais e preservadas, seja como Capoeira Regional ou Capoeira Angola, foi porque entrou em espaço de negociação com a cultura dominante. Nesse processo de influência e ambiguidade, teve que consentir a que certos aspectos fossem apagados e outros destacados. Seus elementos marciais que apontavam para possibilidades de desordem pública e contestação tiveram de ser adormecidos em detrimento da valorização de seus aspectos lúdicos, simbólicos e esportivos. Note-se aqui a diferença entre o caráter esportivo defendido por Mestre Bimba e Pastinha do que foi defendido por outros projetos de capoeira que pretendiam desvinculá-la da sua dimensão étnico e racial como manifestação da diáspora negra

${ }^{22}$ Curioso como essas posições contrárias à política de promoção da igualdade racial já estavam presentes na década de 30 , por ocasião dos Congressos Afro-Brasileiros (PIRES, 2001, p. 329).

${ }^{23}$ Diversos autores apontam como o mito da mestiçagem bem sucedida no Brasil pretende o tempo inteiro construir uma imagem da nação positiva no cenário internacional, diferenciando-se de outros países colonizados e historicamente escravistas que tem o segregacionismo e o conflito como modelo da sociabilidade entre negros e brancos (SOVIK, 2009; SCHWARCZ, 2012). 
e torná-la uma ginástica nacional a ser apropriada pela educação física. Esse projeto permanece existindo até os dias de hoje.

Mesmo tendo sido apropriada pelo discurso hegemônico como imagem e signo brasileiro, tendo contado com a aliança e o apoio de políticos e intelectuais, os dois grandes representantes da capoeira, Mestre Pastinha e Mestre Bimba, bem como os mais velhos mestres de capoeira assim como seus alunos jamais tiveram qualquer benefício e reconhecimento de políticas culturais do Estado. Mesmo difundida em diferentes espaços institucionais - por políticas culturais e educacionais do Estado, em escolas e academias particulares - a capoeira, ao mesmo tempo, que se tornou um bem de consumo, amplamente divulgado e comercializado, conquistou a aparição no discurso hegemônico, mas jamais alcançou o status de cultura dominante. A capoeira nunca deixou de ser uma cultura periférica perto da cultura dominante feita nesse país. Apenas, sua invisibilidade inicial tornou-se uma visibilidade cuidadosamente regulada e segregada, como nas palavras de Hall (2013, p. 377).

Assim, por mais que a capoeira tenha se tornado símbolo nacional, os capoeiristas bem como os mestres de capoeira sabem que circulam no terreno dos estereótipos e preconceitos, em que a visibilidade dada à capoeira, é imediatamente proporcional a sua discriminação por pertencer ao campo da cultura popular, e especificamente, cultura negra (HALL, 2013).

É desta forma que é necessário pensar as relações entre a construção do mito da democracia racial e a capoeira. Penso que nesses termos, o mito da democracia racial deve ser atacado por duas vias: seja pelo racismo a que é submetida a população negra e, consequentemente, a privação e exclusão material e simbólica decorrentes, seja pelo racismo cultural sofrido pelos praticantes das manifestações culturais negras, incluindo a capoeira, o candomblé e o samba.

É nesse sentido que discordo das afirmações de Reis que entende esse processo de positivação e legitimação da capoeira produzidos pela Capoeira Regional e Angola em projetos étnicos e regionais "constituíram, no fundo, duas estratégias possíveis e distintas para a inserção social dos negros naquele momento histórico.” (REIS, 2004, p. 215).

Ou ainda:

No entanto, diferentemente do século 19, quando a prática da capoeira, tolerada como contravenção ou criminalizada, empurrava os negros para fora da sociedade brasileira, agora, com a capoeira-esporte, os negros estão do lado de dentro, estão "no jogo". E para jogar, apresentam duas táticas distintas, que propõem duas maneiras diferentes de inserção social (REIS, 2000, p. 100).

Muito embora a capoeira tenha se incorporado ao discurso oficial e conquistado sua aceitação hegemônica como símbolo de manifestação cultural negra e nacional, não houve efetivamente com isso a inserção social dos negros. Não se pode confundir inserção social com integração e apropriação cultural. $\mathrm{O}$ fato de que a cultura negra tenha sido apropriada por brancos provenientes de classes médias e elites, incorporada e divulgada pelos aparelhos do Estado como símbolo nacional, não significou em hipótese nenhuma mudança nas condições de vida, no acesso aos direitos fundamentais, isto é, não significou qualquer distribuição no privilégio material e simbólico, como de costumenas mãos dos brancos provenientes de outras classes sociais. Ou seja, a integração e a valorização da cultura negra no cenário mais amplo como cultura nacional não implicaram na inserção social dos negros (CARONE; BENTO, 2002; FRY, 2005; MUNANGA, 1996; SCHWARZ, 2012; SOVIK, 2009).

Ora, se na cultura o povo brasileiro brinca, dança, canta, joga, em suma, estabelece relações, se integra e convive de modo harmônico, seria óbvio que no plano das relações sociais também isso se desse. Bem, se sabe como do ponto-de-vista social o país tem lidado com cada uma dessas diferenças e desigualdades de modo trágico. 
Para exemplo da não integração social, cito o modo como os dois baluartes da capoeira que estiveram à frente desse processo de institucionalização, Mestre Pastinha e Mestre Bimba, morreram miseráveis, não encontrando qualquer amparo institucional em vida e em morte para sustentação de uma vida e de uma morte digna. Mestre Bimba teve que ir morar em Goiânia a convite de um de seus alunos para sustentar o mínimo de dignidade de sua vida, deixando a Bahia, uma vez que não havia qualquer política pública dirigida aos mestres de capoeira, bem como políticas públicas que pudessem promover igualdade de direitos sociais e raciais.

O que me derem agora na Bahia não me fará ficar. Não me interessa mais. O que não tiver em Goiânia, terei no cemitério. A Bahia só pra passear. Os governos daqui nunca me deram um palito. Eu precisava ter um centro para ensinar no entanto fiz uma escola no Nordeste de Amaralina à força do meu braço. Ninguém me ajudou. E eu conheço o folclore como ninguém. Ir para Goiás é uma necessidade financeira (TRIBUNA DA BAHIA, 1972 apud REIS, 2000, p. 109).

Por sua vez, Mestre Pastinha morre num asilo, cego e doente, e iria ser enterrado em caixão de indigente, não fossem os esforços de sua mulher na venda de acarajé (REIS, 2000, 2004).

Em entrevista à Tribuna da Bahia de 7 de fevereiro de 1974, Pastinha revelaria o descaso das autoridades baianas, as quais não the haviam providenciado outro lugar para ensinar. Muito doente, mudou-se para um quarto pequeno e sem ventilação na rua Alfredo Brito, 14, no Pelourinho. Em fins de 1979, sofreu um derrame cerebral. Após um ano de internação num hospital público, foi recolhido ao Abrigo D. Pedro II, onde viria a falecer aos 2 anos, em 14 de outubro de 1981 (REIS, 2004, p. 214)

Se os grandes mestres de capoeira, reconhecidos nacionalmente como representantes da arte não obtiveram qualquer amparo em políticas culturais, a não ser apoio circunstancial e baseado no favor de alguns políticos e intelectuais, como não pensar no restante da população negra no Brasil?

\section{Conclusão}

Todas essas contribuições ajudam a olhar o campo de pesquisa da capoeira como um campo de luta cultural que pode assumir diferentes formas e contatos com a cultura dominante e a cultura nacional. Sem dúvida, a capoeira como uma prática social popular ocupou e ocupa diferentes papéis no discurso: oscilando entre a repressão aberta, a incorporação, a distorção, a folclorização, a invisibilidade e a espetacularização. De certa forma, Pires $(2001,2010)$ sugere que os discursos da capoeira que nasceram na Primeira República e no Estado Novo permanecem lançando até hoje as estratégias fundamentais de relacionamento e negociação da capoeira com o Estado. Entre as estratégias de embranquecimento pela vinculação da capoeira ao esporte ou a luta, perdendo sua relação com a cultura negra e estratégias que se apropriam de práticas e discursos contra hegemônicos, constituindo novos blocos de alianças, sobre a necessidade de descentração dos saberes eurocêntricos, pelo ensino da história e cultura negra de modo afro-centrado, isto é, uma estratégia de valorização da cultura negra, especialmente na Capoeira Angola. Entretanto, é fundamental pensar em que medida a Capoeira Angola permanece consentindo e resistindo ao mito da democracia racial e de que forma os mestres e capoeiristas podem e tem usado desse espaço para de fato ampliar o debate sobre as desigualdades raciais entre o negro e o branco na sociedade brasileira.

\section{Agradecimentos}

Agradeço ao CNPq pela concessão de bolsa de estudos ao Programa de Pós-Graduação do Instituo de Psicologia da Universidade de São Paulo.

\section{Referências}

ANDERSON, B. Comunidades imaginada: reflexões sobre a origem e a difusão do nacionalismo. São Paulo: Companhia das Letras, 1991. 
AREIAS, W. O que é capoeira? São Paulo: Brasiliense, 1983.

BOSI, A. Dialética da colonização. São Paulo: Companhia das Letras, 1992.

BOSI, E. O tempo vivo da memória: ensaios de psicologia social. São Paulo: Ateliê, 2003.

CARONE, I.; BENTO, M. A. S. Psicologia social do racismo. Petrópolis: Vozes, 2002.

CERTEAU, M. A invenção do cotidiano. Petrópolis: Vozes, 2014.

CHAUI, M. Conformismo e resistência: aspectos da cultura popular no Brasil. São Paulo: Brasiliense, 1984.

CLIFFORD, J. A experiência etnográfica: antropologia e literatura no século XX. Rio de Janeiro: UFRJ, 1998.

DANTAS, B. G. Vovô nagô e papai branco: usos e abusos da África no Brasil. 1982. Dissertação (Mestrado) - UNICAMP, Campinas, 1982.

FRY, P. A persistência da raça. Rio de Janeiro: Civilização Brasileira, 2005.

FUNDAÇÃO CULTURAL PALMARES. Capoeira vira patrimônio cultural brasileiro. Disponível em: $<$ http://www.palmares.gov.br/?p=2744\&lang=es $>$. Acesso em: 7 ago. 2016.

HALL, S. Aidentidade cultural na pós-modernidade. Rio de Janeiro: Lamparina, 2014.

HALL, S. Da diáspora: identidade e mediações culturais. Belo Horizonte: UFMG, 2013.

HELLER, A. O cotidiano e a história. São Paulo: Paz e Terra, 2004.

INSTITUTO DO PATRIMÔNIO HISTÓRICO E ARTÍSTICO NACIONAL (Brasil). Roda de capoeira. Disponível em: < http://portal.iphan.gov. br/pagina/detalhes/66>. Acesso em: 23 mar. 2017.
MUNANGA, K. Mestiçagem e experiências interculturais no Brasil. In: SCHWARCZ, L. K. M.; SOUZA, L. V. (Org.). Negras imagens: ensaios sobre cultura e escravidão no Brasil. São Paulo: Edusp/Estação Ciência, 1996. p. 179-194.

ORTIZ, R. Cultura brasileira e identidade nacional. São Paulo: Brasiliense, 2003.

PIRES, A. L. C. S. Movimentos da cultura afro-brasileira: a formação histórica da capoeira contemporânea 1890-1950. 2001. Tese (Doutorado) - Universidade Estadual de Campinas, Campinas, 2001.

PIRES, A. L. C. S. Os intelectuais, a capoeira e os símbolos étnicos no Brasil. In: ENECULT - ENCONTRO DE ESTUDOS MULTIDISCIPLINARES EM CULTURA, 2010, Salvador. Anais... Salvador: FACOM/UFBA, 2010.

REIS, L. V. S. Mestre Bimba e Mestre Pastinha: a capoeira em dois estilos. In: SILVA, V. G. Artes do corpo: memória afro-brasileira. São Paulo: Selo Negro, 2004.

REIS, L. V. S. O mundo de pernas para o ar: a capoeira no Brasil. São Paulo: Publisher Brasil, 2000.

SCHMDIT, M. L. S. Pesquisa participante: alteridade e comunidades interpretativas. Psicologia USP, São Paulo, v. 17, n. 2, p. 11-41, 2006.

SCHWARCZ, L. M. Nem preto, nem branco, muito pelo contrário. São Paulo: Claro Enigma, 2012.

SOVIK, L. Aqui ninguém é branco. Rio de Janeiro: Aeroplano, 2009.

VASSALO, S. P. Capoeiras e intelectuais: a construção coletiva da capoeira "autêntica". Estudos Históricos, Rio de Janeiro, n. 32, p. 104-124, 2003. 
